\title{
Recovery of atrial systolic function after pharmacological conversion of chronic atrial fibrillation to sinus rhythm: a Doppler echocardiographic study
}

\author{
Albino Jović, Rosana Troskot
}

\begin{abstract}
Objective-To evaluate the time course of the recovery of atrial mechanical function after pharmacological cardioversion of chronic atrial fibrillation to sinus rhythm. Patients and methods-21 patients (12 male, 9 female, aged 37-77 years) with chronic atrial fibrillation ( $<6$ months) were followed up by serial transmitral pulsed Doppler echocardiography. Echocardiographic studies were performed within the first 24 hours and on day 8,15 , and 30 after cardioversion.

Results-There was a significant increase (mean (SD)) in the peak $A$-wave velocity (from $0.35(0.10)$ on day 1 to $0.50(1.73)$ on day 8 , and thereafter a gradual increase to $0.61(0 \cdot 14) \mathrm{m} / \mathrm{s}$ on day 30$)$. Similarly, integrated late atrial velocities increased from $4.50(1.46)$ on day 1 to $5.61(1.73)$ on day 8 and $5.97(1.47) \mathrm{cm} / \mathrm{s}^{2}$ on day 30 . The atrial contribution to total transmitral flow increased significantly from 26 (7)\% immediately after conversion of atrial fibrillation to sinus rhythm to 34 (7)\% on day 30 , indicating the haemodynamic benefit of the restoration of sinus rhythm. Left atrial diameter decreased but not significantly, from $4 \cdot 11(0.37)$ to $3.98(0.34) \mathrm{cm}$ $(P<0.005)$.

Conclusions-These results suggest that restoration of atrial mechanical function after pharmacological cardioversion in patients with chronic atrial fibrillation is slow and gradual, as it is after electrical DC restoration of sinus rhythm. This time course may have important implications for determining how long treatment with anticoagulants and antiarrhythmic agents needs to continue in individual patients. It will also influence the clinical assessment of the haemodynamic benefit of restoring sinus rhythm in patients with chronic atrial fibrillation.
\end{abstract}

(Heart 1997;77:46-49)

Department of Medicine, Zadar General Hospital, Zadar, Croatia A Jović $\mathrm{R}$ Troskot

Correspondence to: Dr A Jović, Department of Medicine, Zadar General Hospital, B. Peričića 3 HR-23000 Zadar, Croatia. Accepted for publication 18 July 1996 leads to the loss of organised electrical and mechanical atrial activity. ${ }^{12}$ The steady increase in the prevalence of AF has been attributed to increased life expectancy and the greater proportion of elderly people with car- diovascular diseases. The incidence of $\mathrm{AF}$ in the general population is $0.4 \%$. In those over 65 years of age it rises to $4 \%$, and about half those with this arrhythmia are older than $75 .^{2-5}$

In more than $75 \%$ of elderly $\mathrm{AF}$ patients, the aetiology includes arterial hypertension and sick sinus syndrome, whereas mitral valve disease, thyrotoxicosis, alcohol, anaemia, pericarditis, and cardiosurgical procedures are important aetiological factors in younger patients. ${ }^{4}$ Elimination of these factors is a precondition for achieving sinus rhythm, and vital for maintaining it. However, in $3 \%$ to $31 \%$ of cases, AF occurs as an isolated event ("lone atrial fibrillation") without a recognisable cause or structural heart disease. ${ }^{5-7}$

In each patient with $A F$ the aim of treatment is to restore sinus rhythm. This can be achieved by antiarrhythmics or electrical cardioversion. Immediately after conversion of AF to sinus rhythm, atrial electrical activity becomes normal, but what is the time course of recovery and is atrial contractile function restored? Atrial mechanical activity and contractile systolic activity have been shown to recover gradually, within a few hours to several weeks. ${ }^{8-10}$ Recently, Doppler echocardiography has been most commonly used as the most appropriate, non-invasive method of visualising transmitral flow to assess left ventricular diastolic function, including the contractile contribution of the left atrium. ${ }^{11-14}$

The aim of this study was to determine the dynamics of recovery and restoration of atrial systolic function after pharmacological conversion to sinus rhythm in patients with chronic $\mathrm{AF}$, by measuring transmitral diastolic flow by Doppler echocardiography.

\section{Patients and methods}

STUDY POPULATION

We studied 21 patients (12 men and nine women aged 27-77 years, mean age 61(9)) with chronic AF. Twelve had no signs of structural heart disease or risk factors for $A F$, so they probably had isolated AF, so-called lone atrial fibrillation. Of the remaining nine patients, one had experienced cardiac infarction and had raised blood pressure, one had diabetes mellitus and raised blood pressure, and one had angina pectoris and raised blood pressure. Of the remaining six patients, two patients had raised blood pressure, and one each had diabetes mellitus, angina pectoris, hyperlipidaemia, and history of cerebrovascular accident.

Conversion of $\mathrm{AF}$ to sinus rhythm was 
Doppler transmitral flow velocity variables (mean (SD))

\begin{tabular}{|c|c|c|c|c|c|}
\hline & \multicolumn{5}{|c|}{ Timing of measurement } \\
\hline & Day 1 & Day 8 & Day 15 & Day 30 & $P($ day $1 v$ day 30$)$ \\
\hline $\begin{array}{l}\text { Peak E }(\mathrm{cm} / \mathrm{s}) \\
\text { Peak A }(\mathrm{cm} / \mathrm{s}) \\
\text { E-VTI }\left(\mathrm{cm} / \mathrm{s}^{2}\right) \\
\text { A-VTI }\left(\mathrm{cm} / \mathrm{s}^{2}\right) \\
\text { A/VTI-total }(\%) \\
\text { E/A } \\
\text { E-VTI/A-VTI } \\
\text { VTI-total }\left(\mathrm{cm} / \mathrm{s}^{2}\right)\end{array}$ & $\begin{array}{r}0.91(0.19) \\
0.35(0.10) \\
11.55(2.11) \\
4.50(1.46) \\
26(7) \\
2.78(1.10) \\
2.84(1.7) \\
17.14(2.97)\end{array}$ & $\begin{array}{r}0.78(0.16) \\
0.50(0.16) \\
10.84(1.92) \\
5.61(1.73) \\
33(9) \\
1.83(0.79) \\
2.27(1.01) \\
17.20(2.37)\end{array}$ & $\begin{array}{r}0.75(0.11) \\
0.58(0.14) \\
10.89(2.30) \\
6.04(1.55) \\
33(7) \\
1.37(0.44) \\
1.84(0.56) \\
18.28(3.20)\end{array}$ & $\begin{array}{r}0.72(0.11) \\
0.61(0.14) \\
10.46(2.07) \\
5.97(1.47) \\
34(7) \\
1.30(0.48) \\
1.86(0.56) \\
17.43(3.21)\end{array}$ & $\begin{array}{l}<0.005 \\
<0.005 \\
\text { NS } \\
<0.005 \\
<0.005 \\
<0.005 \\
<0.005 \\
\text { NS }\end{array}$ \\
\hline
\end{tabular}

A-VTI, integrated velocity of late transmitral diastolic flow; E-VTI, integrated velocity of early transmitral diastolic flow; Peak-A maximal velocity of late transmitral diastolic flow; peak-E, maximal velocity of early transmitral diastolic flow; VTI-total, integrated velocity of total transmitral diastolic flow.

achieved by quinidine in a mean (SD) dose of 1600 (400) mg daily. All patients had been taking individually determined oral doses of anticoagulant for at least a month before the study. Quinidine was well tolerated by the patients. No major side effects, except for mild gastrointestinal discomfort, were reported. In addition to quinidine sulphate, the patients were treated with digitalis (two patients), $\beta$ blockers (two patients), calcium antagonists (six patients), and propafenone (two patients).

\section{DOPPLER ECHOCARDIOGRAPHIC ANALYSIS}

Echocardiographic studies were performed on an Ultramark 7 (ATL) device with a $2.5 \mathrm{MHz}$ electronic probe. Transmitral flow was measured by pulsed Doppler from an apical four chamber view in the left lateral position. The sample volume was applied to the tips of the mitral valve leaflets, as previously described in a study that evaluated left ventricular diastolic function from transmitral flow. ${ }^{15}$

The following variables were analysed from three succesive cardiac cycles: maximal and integrated velocity of early transmitral diastolic flow (E, E-VTI), maximal and integrated velocity of late transmitral diastolic flow (A, AVTI), and integrated velocity of total transmitral diastolic flow (VTI-total).

The following variables were determined from the parasternal long and short axis: left atrial diameter (LA) and diastolic and systolic left ventricular diameter (LVd and LVs). Mitral regurgitation was detected and evaluated by pulsed and colour Doppler.

All measurements were carried out within the first 24 hours (first measurement), and on day 8 (second measurement), day 15 (third measurement), and day 30 (fourth measurement) after conversion of AF to sinus rhythm.

Figure 1 Peak transmitral $A$ and $E$ velocity after conversion to sinus rhythm. $A$, atrial contraction wave; $E$, early filling wave.

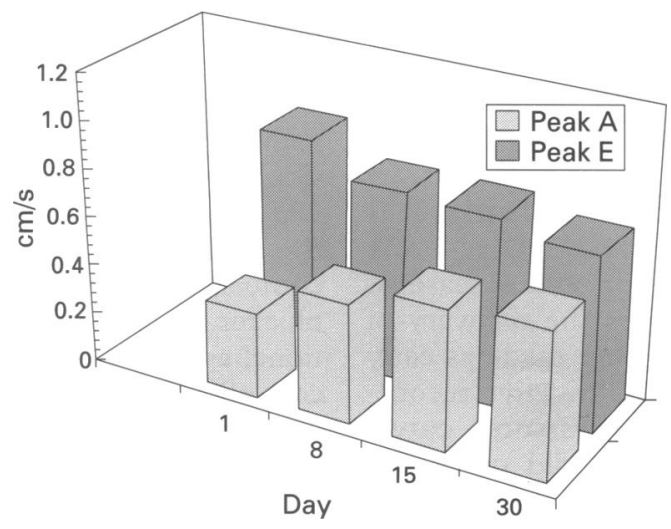

Examinations were videotaped using a Panasonic $7330 \mathrm{E}$ videorecorder, for subsequent measurements and thorough analysis of the findings by a blinded observer.

\section{STATISTICAL ANALYSIS}

Statistical significance for paired samples (observation pairs) was determined by the test of differences of arithmetical means at the 0.005 level of significance.

The protocol was approved by the investigational review board of the hospital and all participants gave informed consent.

\section{Results}

In all patients the $A$ wave of transmitral flow appeared immediately after pharmacological conversion of AF to sinus rhythm, indicating recovery of left atrial contractile function. Unlike in other studies, ${ }^{16}{ }^{17}$ a missing A wavea sign of atrial standstill or stunning - which is probably characteristic of some patients after DC shock electroconversion, ${ }^{18}{ }^{19}$ was not recorded in any of our patients. Results are presented in the table.

The greatest decrease in the maximal velocity of early diastolic left ventricular filling ( $E$ wave) occurred from day 1 to the second examination (day 8 after sinus rhythm recovery), thereafter it continued to decrease gradually until day 30. Maximal transmitral flow velocity at the time of atrial contraction (A wave) increased gradually from the first to the fourth measurement, resulting in a gradual but significant decrease in the ratio of maximal $\mathrm{E}$ wave and $A$ wave velocities (fig 1 ). The values and ratio of integrated velocities of the $A$ and $E$ waves followed a similar pattern of changes (table, fig 2), but integrated velocities of total transmitral flow (VTI-total) did not change significantly during the month of monitoring, suggesting a compensatory pattern of changes in particular phases of the left ventricular diastolic filling. However, there were significant changes in the atrial contribution to total transmitral flow (A/VTI-total), which was 26 (7)\% immediately after conversion, and gradually and steadily increased, reaching 34 (7)\% on day 30 and confirming the haemodynamic benefit of sinus rhythm restoration in our patients (table, fig 3).

During the one month follow up, no substantial changes were recorded in the left atrial diameter (LA). On days 1 and 30 it was $4 \cdot 11$ $(0.37)$ and $3.98(0.39) \mathrm{cm}$, respectively, but 


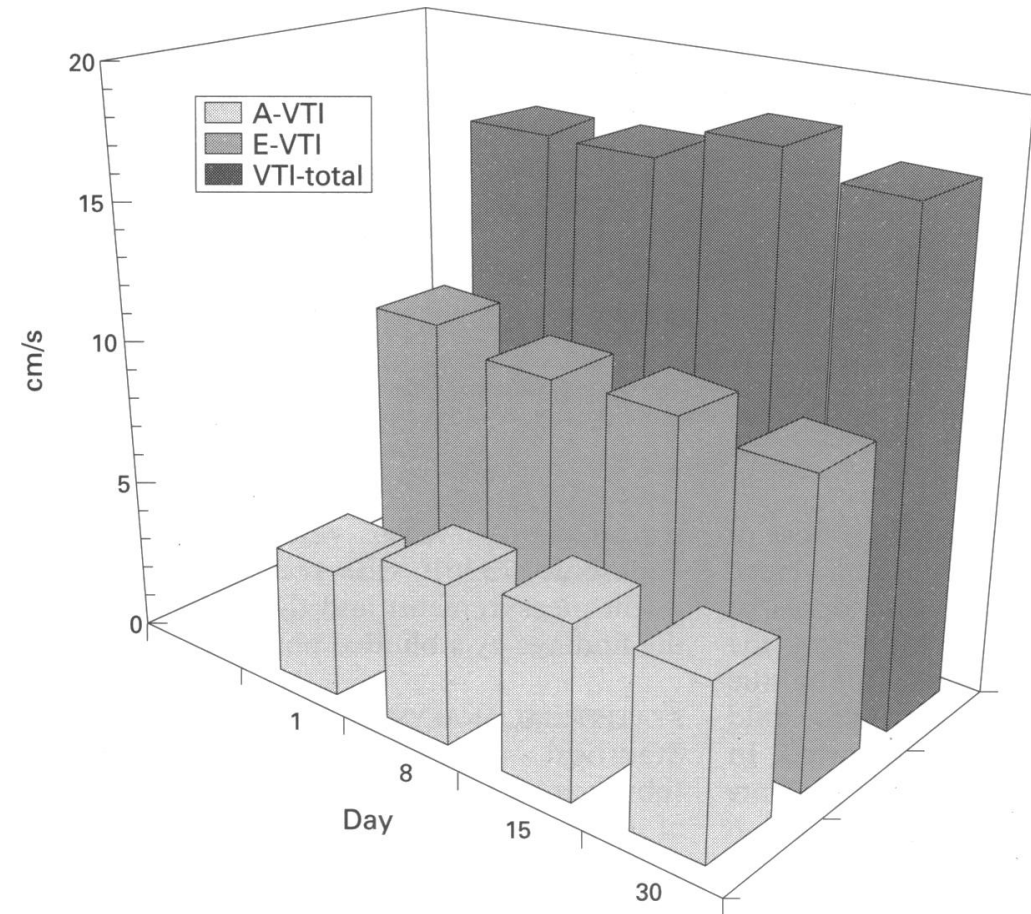

Figure 2 Integrated velocity of early, late, and total diastolic filling after conversion to sinus rhythm. A-VTI, integrated velocity of late transmitral diastolic flow; $E-V T I$, integrated velocity of early transmitral diastolic flow; VTI-total, integrated velocity of total transmitral diastolic flow.

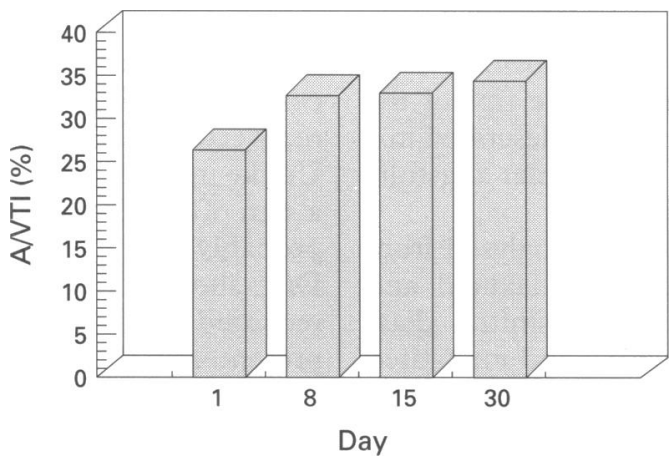

Figure 3 Change in the percentage atrial contribution to total transmitral flow. $A$, atrial contraction wave; VTI, integrated velocity of total transmitral diastolic flow.

the decrease was not statistically significant $(P<0.005)$. Neither did the left ventricular size undergo any significant changes during the period of observation. On days 1 and 30 diastolic left ventricular diameter (LVd) was $5.23(0.38)$ and $5.20(0.27) \mathrm{cm}$ and systolic left ventricular diameter was $3.37(0.28)$ and $3.35(0.29) \mathrm{cm}$, respectively $(\mathrm{P}<0.005)$.

\section{Discussion}

In chronic $A F$, recovery of atrial contractile function may vary greatly from patient to patient, depending on a number of factors. ${ }^{1920}$ Proper evaluation of the intensity of atrial contractile function and time of definite recovery is important to a clinician for several reasons. That is why efforts to assess the recovery of atrial mechanical function were made as early as nearly 30 years ago, using invasive recording of the intra-arterial pressure curve. Recovery of atrial contraction did not occur immediately after conversion, but proceeded gradually, with the initial haemodynamic contribution being undetectable. ${ }^{2122}$

Before the introduction of Doppler echocardiography in clinical practice, Ikram et $a l^{23}$ and Malich et $a l^{24}$ confirmed these observations from invasive studies by non-invasive apex kinetocardiography. They also concluded that in most patients, atrial contraction is generally restored within the first 24 hours.

Doppler echocardiographic analysis of transmitral flow has proved to be the method of choice for this purpose. ${ }^{1425}$ Using this method, Dethy et $a l^{17}$ found that patients who had a rapid improvement in atrial contractility had a better outcome in terms of successful maintenance of sinus rhythm: this finding was not confirmed by others. ${ }^{8}$ However, such assessment is crucial in deciding to continue antiarrhythmic therapy and in determining the duration and dose of anticoagulant required after sinus rhythm has been restored.

Maximal A wave and $\mathrm{E}$ wave velocities, their ratio, and the atrial contribution to total transmitral flow are adequate indices for accurately determining the time that atrial function recovers, and both can be measured easily by Doppler echocardiography and precisely evaluated in most patients.

A slower recovery and occasionally even complete absence of atrial contraction (socalled atrial standstill or stunning) might in part be attributed to the effect of DC shock on atrial inotropism. Manning et $a l^{12}$ found that among patients with chronic AF recovery of atrial mechanical function was dependent on the duration of $\mathrm{AF}$ before cardioversion. However, among patients who had had $\mathrm{AF} \leqslant 5$ weeks, recovery of atrial mechanical function seemed to be related to the mode of cardioversion, and atrial contractility was restored more rapidly in patients undergoing pharmacological cardioversion than those undergoing electrical cardioversion. ${ }^{13}$

In the present study analysis of the Doppler echocardiographic curve of transmitral flow showed the greatest changes in the A wave, where maximal velocities markedly increased from $0.35(0.10)$ on day 1 to $0.61(0.14) \mathrm{cm} / \mathrm{s}$ on day $30(\mathrm{P}<0.005)$, along with a striking change in E/A ratio from $2.78(1.10)$ to 1.30 $(0.48)(P<0.005)$. The atrial contribution to total transmitral flow (fig 3 ) changed significantly, thus clearly confirming the haemodynamic benefit of achieving sinus rhythm. In our patients AF had lasted more than six months and recovery of atrial contractile function was most intense within the first 24 hours, with a considerable gradual improvement during the subsequent 30 days. The results of our study resemble those after electrical cardioversion in patients with prolonged AF. Cardioversion in our patients was achieved by the administration of quinidine, in some cases combined with digitalis, $\beta$ blocker, calcium blocker, or propafenone. However, these additional agents were unlikely to have any significant effect on the results obtained.

Our results suggest that in patients with pharmacological AF conversion to sinus rhythm, as in those in whom sinus rhythm is 
restored by DC shock, atrial contraction function gradually returns to normal. This implies two important messages for clinicians. Firstly, anticoagulant therapy should be continued for at least a month, because the initial atrial contractility is quite weak and the risk of thrombus formation within the atria persists even after sinus rhythm is restored. Monitoring of the dynamics of restoration of atrial mechanical function in each individual patient helps to detect those who are likely to need treatment for longer or even permanently. Secondly, the benefit of restoring sinus rhythm in patients with chronic AF needs be evaluated for at least a month, and in some patients for longer. Earlier evaluation may underestimate the therapeutic effects of restoring sinus rhythm.

Positive conclusions, for example, about the duration of the sinus rhythm likely to be achieved, based on Doppler echocardiographic analysis of the pattern of changes in transmitral flow, after medical conversion of chronic AF to sinus rhythm require clinical trials with long term follow up.

1 Havranek EP. Management of atrial fibrillation: curren perspectives. Am Fam Physician 1994;50:959-68.

2 Kannel WB, Wolf PA. Epidemiology of atrial fibrillation. In: Falk RH, Podrid PJ, eds. Atrial fibrillation, mechanism In: Falk RH, Podrid PJ, eds. Atrial fibrillation, mechanism

3 Petersen P, Godtfredsen J. Atrial fibrillation-a review of Petersen P, Godtfredsen J. Atrial fibrillation--a review
course and prognosis. Acta Med Scand 1984;216:5-9.

4 Benjamin EJ, Levy D, Vayiri SM, D'Agostino RB, Belange AJ, Wolf PA, et al. Independent risk factors for atrial fibrillation in a population-based cohort: the Framingham Heart Study. $\mathscr{f} A M A$ 1994;271:840-4.

5 Pritchett ELC. Management of atrial fibrillation. $N$ Engl Med 1992;326:1264-71.

6 Kopecky SL, Gersh BJ, McGoon MD, Whisnant JP, Holmes DR, Ilstrup DM, et al. The natural history of lone atrial fibrillation. A population-based study over three decades. N Engl f Med 1987;317:669-74.

7 Davidson E, Rotenberg Z, Weinberger I, Fuchs J, Agmon J. Diagnosis and characteristics of lone atrial fibrillation. Diagnosis and characte

8 Manning WJ, Leeman DE, Gotch PJ, Come PC. Pulsed Doppler evaluation of atrial mechanical function after electrical cardioversion of atrial fibrillation. Am $\mathcal{f}$ Coll Cardiol 1989;13:617-23.

9 Jordaens L, Missault L, Germonpre E, Callens B, Adang L van den Bogaerde J, et al. Delayed restoration of atrial function after conversion of atrial flutter by pacing or electrical cardioversion. Am ₹ Cardiol 1993;71:63-7.

10 Mattioli AV, Tarabini-Castellani E, Vivoli D, Molinari R Il ripristino della funzione meccanica atriale dopo fibrilIl ripristino della funzione meccanica atrial

11 Luleci C, Aytug N, Isik A, Arslan N, Perk M. Doppler evaluation of atrial function of mitral flow after cardioversion from atrial fibrillation. In: Drinković N, DeMaria $\mathrm{AN}$, eds. Proceedings of the International Conference on Cardiac Doppler and Color Flow Imaging. Zagreb, 1990: 99-106.

12 Manning WJ, Silverman DI, Katz SE, Riley MF, Come PC, Doherty RM, et al. Impaired left atrial mechanical function after cardioversion: relation to the duration of atrial fibrillation. Am f Coll Cardiol 1994;23:1535-40.

13 Manning WJ, Silverman DI, Katz SE, Riley MF, Doherty $\mathrm{RM}$, Munson JT, et al. Temporal dependence of the RM, Munson JT, et al. Temporal dependence of the return of atrial mechanical function on the mode of car-
dioversion of atrial fibrillation to sinus rhythm. $A m \mathcal{7}$ dioversion of atrial fib
Cardiol 1995;75:624-6.

14 Thomas JD, Weyman AE. Echocardiographic Doppler evaluation of left ventricular diastolic function. Circulation 1991;84:977-90.

15 Jović A, Troskot R, Nekić-Borčilo $M$. Effect of heart rate on left ventricular diastolic transmitral flow velocity patterns assessed by Doppler echocardiography in norma subjects. Cardiol Hung 1995;suppl: 16.

16 Orlando JR, van Herick R, Aronow WS, Olson HG. Hemodynamics and echocardiograms before and after cardioversion of atrial fibrillation to normal sinus rhythm. Chest 1979;76:521-6.

17 Dethy M, Chassat C, Roz D, Mercier LA. Doppler echocardiographic predictors of recurrence of atrial fibrillation after cardioversion. Am $\mathcal{F}$ Cardiol 1988;62:723-6.

18 O'Neill PG, Puleo PR, Bolli R, Rokey R. Return of atria mechanical function following electrical conversion of atrial dysrhythmias. Am Heart f 1990;120:353-9.

19 Falk RH, Podrid PJ. Electrical cardioversion of atrial fibrillation. In: Falk RH, Podrid PJ, eds. Atrial fibrillation, mechanisms and management. New York: Raven Press, 1992; 181-95.

20 Murgatroyd FD, Camm AJ. Atrial arrhythmias. Lancet 1993;341:1317-22.

21 Scott ME, Patterson GC. Cardiac output after direct current conversion of atrial fibrillation. Br Heart $\mathcal{F} 1969 ; 31$ 87-90.

22 Resnekov L. Haemodynamic studies before and after electrical conversion of atrial fibrillation and flutter to sinus rhythm. Br Heart F 1969;29:700-8

23 Ikram $\mathrm{H}$, Nixon PGF, Arcan T. Left atrial function after electrical conversion to sinus rhythm. $\mathrm{Br}$ Heart $f$ 1968;30:80-3.

24 Malich J, Schweizer W, Burkat F. Atrial function after cardioversion for atrial fibrillation. Br Heart f 1973;35:24-7.

25 Ferguson JJ III, Manning WJ, Come PC. Pulsed Doppler echocardiographic determination of the time course of left ventricular filling: validation with cineangiography. Am Heart f 1989;117:127-32. 